\title{
Genetic Diversity Analysis in Exotic Hybrid Rice Genotypes Grown During Wet Season in Bangladesh
}

\author{
A. Ahmed ${ }^{1}$, S. G. Shaon ${ }^{2}$, M. S. Islam², P. S. Saha ${ }^{1}$ and M. A. Momin ${ }^{3}$ \\ ${ }^{I}$ BRAC Agricultural Research and Development Centre, Gazipur; ${ }^{2}$ Agriculture and Food Security \\ Program, BRAC, Dhaka; ${ }^{3}$ Bangladesh Rice Research Institute (BRRI), Gazipur, Bangladesh
}

*Corresponding author and Email: ashick.ahmed@brac.net

Received: 23 March 2015

Accepted: 12 December 2015

\begin{abstract}
Two experiments were conducted with 43 IRRI developed $F_{1}$ hybrid rice genotypes (HRDC) for ten agronomic characters in a randomized complete block design to study the genetic diversity through multivariate analysis in Gazipur and Pabna districts, respectively during wet season 2013. On the basis of $\mathrm{D}^{2}$ values, the genotypes were grouped into five different clusters. During wet season, cluster III comprised maximum number of genotypes (15). The data obtained across locations showed that there are significant differences among HRDC genotypes for all growth parameters, yield and yield components. The highest yield (5.65 $\left.\mathrm{t} \mathrm{ha}^{-1}\right)$ was observed in HRDC 1341 because of produced heaviest panicle (4.28 g) and the lowest $\left(2.48 \mathrm{t} \mathrm{ha}^{-1}\right)$ in HRDC 1311 because of obtained lowest fertility (49.9 $\%)$ and 1000-grain wt. (12.9 g), respectively. The maximum inter-cluster distances were observed between cluster I and V (11.63) and the minimum between cluster III and IV (2.35). The highest intracluster distance (1.73) was observed in cluster III and minimum in cluster I (0.00), since it consisted with one genotype. Difference in cluster means existed for almost all the characters studied. Among the characters, growth duration, spikelet panicle ${ }^{-1}$, fertility $(\%)$ and 1000 -grain wt contributed the most for divergence in the genotypes. The highest mean values for fertility percentage, panicle weight and 1000 grain wt. but early flowering and short maturing genotypes were grouped into Cluster II followed by Cluster III and IV indicating that the genotypes have genetic potentiality to contribute better for yield maximization of hybrid rice.
\end{abstract}

Keywords: Genetic diversity, cluster, $\mathrm{F}_{1}$ hybrid rice genotypes, multivariate analysis

\section{Introduction}

Production of rice (Oryza sativa L.) in Bangladesh has to be increased by at least $60 \%$ to meet up food requirement of the increasing population by the year 2020 (Masum, 2009). To achieve this target, rice yield should increase to $5.5 \mathrm{t} \mathrm{ha}^{-1}$ compared to $2.8 \mathrm{t} \mathrm{ha}^{-1}$ at present (Bhuiyan, 2002). But there is a little scope to increase rice area. Moreover, the arable land is decreasing at the rate of $1 \%$ per annum (BBS,
2011). The yield ceiling of modern rice varieties has been plateaued (Bhuiyan, 2002). Julfiquar et al. (2002) reported that hybrid rice is an alternative to break the present yield ceiling of semi-dwarf modern varieties in Bangladesh. Efforts aimed at breaking the yield barrier in rice have been amply demonstrated by Lanceras et al. (2004), Degenkolbe et al. (2009); Akhter et al. (2003) and Chen et al. (2009). It has been proved practically in China that hybrid rice has more than $20 \%$ yield advantage over improved inbred 
varieties (Tiwari et al., 2011). In Bangladesh, hybrid rice gains positive response in dry season and a few varieties have been cultivated in wet season (Moinul and Biswas, 2011). The national average yield of rice in Bangladesh during the wet season is very low at around $2.29 \mathrm{t} \mathrm{ha}^{-1}$ (BBS, 2012), whereas it is $3.8 \mathrm{t} \mathrm{ha}^{-1}$ in south-east Asian country.

In Bangladesh, research and development of hybrid rice technology was initiated in 1993 with the introduction of rice hybrids and parent materials from International Rice Research Institute (IRRI). Peng et al. (2003) reported that the average yield of $\mathrm{F}_{1}$ hybrid rice was $17 \%$ higher than that of indica inbred in the 1998 wet season. Significant emphasis is being given to comprehensive analysis of genetic diversity in numerous field crops and maximum exploitation of the genetic resources (Belaj et al., 2002). Hybrid Rice Research and Development Consortium (HRDC) were inaugurated in 2008 at IRRI to accelerate the adoption of the technology.

Keeping in view the above facts, a number of 43 IRRI developed hybrid rice genotypes were tested in two different agro-ecological zones of Bangladesh to estimate the nature and magnitude of genetic divergence and characters contributing to the genetic divergence of these genotypes during wet season.

\section{Materials and Methods}

\subsection{Experimental Design and Treatments}

On farm trials were conducted with $43 \mathrm{~F}_{1}$ hybrid rice lines from IRRI along with popular BRAC hybrid Aloran, Shakti-2 and BRRI dhan39 (inbred) in two locations-BRAC Agricultural Research and Development Centre (BARDC), Gazipur and Dashuria Seed Farm, Pabna, respectively in a Randomized Complete Block Design (RCBD) with three replications during wet season of 2013. Each plot measures 4.0 meter long and 2.0 meter wide in BARDC and 3.8 meter long and 2.2 meter wide in Dashuria Seed Farm.

\subsection{Crop establishment and management}

Seedlings for each genotype were separated, labelled and these were bundled in convenient sizes. Seedlings of each genotype were transplanted in each designated plot. 23-26 days old seedlings of the genotypes were transplanted at one seedling per hill as a standard practice on a straight row at spacing of $20 \mathrm{~cm}$ x $20 \mathrm{~cm}$. Gap filling was done a week after transplanting. Urea, TSP, MoP, Gypsum and $\mathrm{ZnSO}_{4}$ fertilizer were applied at $180-80-70-60-10 \mathrm{~kg} \mathrm{ha}^{-1}$. The whole amount of TSP, Gypsum, two third of MoP and one third of urea were mixed and applied as basal application. $\mathrm{ZnSO}_{4}$ was applied separately to avoid fixation with Phosphorus. The remaining urea was applied in two equal splits at maximum tillering stage and just before panicle initiation stage. The rest amount of MoP was applied before panicle initiation stage. Weeding was done two to three times and insecticides were applied as and when necessary to keep the fields free from insects-pests. All other recommended cultural management practices were followed to ensure good crop stand.

\subsection{Measurements of Parameters}

Three hills (excluding border hills) from each plot were selected and tagged after transplanting for taking yield and yield components data at harvest. Morphological data were collected for ten quantitative characters at the appropriate growth stage of rice plants following the description for Oryza sativa L. (IRRI, 2002). The crop was harvested at maturity; the weight of grains was adjusted to $14 \%$ moisture content. Plant height $(\mathrm{cm})$, panicles no. $\mathrm{m}^{-2}$, days to $50 \%$ flowering; growth duration (days), panicle length $(\mathrm{cm})$, spikelet panicle ${ }^{-1}$, panicle weight $(\mathrm{g})$, spikelet fertility (\%), 1000 grain weight (g) and grain yield $\left(\mathrm{t} \mathrm{ha}^{-1}\right)$ were measured.

\subsection{Data Analysis}

The collected data were analyzed statistically following PCA and Mahalanobis (1936) generalized distance $\left(\mathrm{D}^{2}\right)$ extended by Euclidean and clustering by Ward's (1963) method. Statistical analysis was carried out using computer software STAR version 2.0.1 (2014). 


\section{Results and Discussion}

The data obtained across locations showed that there are significant differences among HRDC genotypes for all growth parameters, yield and yield components (Table 1). The plant height $(\mathrm{PH})$ ranges between 108 and $143 \mathrm{~cm}$. Among the genotypes, the highest height of $143 \mathrm{~cm}$ was recorded in HRDC 1326 while the lowest, 108 $\mathrm{cm}$ in HRDC 1349. Shorter plant height is an important character of the hybrid to withstand lodging. The panicle no. $\mathrm{m}^{-2}\left(\mathrm{PM}^{-2}\right)$ was significantly affected by genotypes which varied from 131 for HRDC 1340 to 239 for HRDC 1350. Days to $50 \%$ flowering (FD) and crop growth duration (CGD) was shortest in Shakti-2 and Aloran, taking 79 and 113 days, respectively while the longest in HRDC 1319, taking 102 and 128 days, respectively. The longest panicle $(30.57 \mathrm{~cm})$ was produced by HRDC 1326 while the shortest $(24.5 \mathrm{~cm})$ by HRDC 1313 . The heaviest panicle $(4.28 \mathrm{~g})$ was produced by HRDC 1341 while the lightest $(1.47 \mathrm{~g})$ by HRDC 1349. Spikelet panicle ${ }^{-1}\left(\mathrm{SP}^{-1}\right)$ is one of the most important yield components and probably this character will be helpful in breaking the yield plateau. Spikelet panicle ${ }^{-1}$ differs significantly among the tested genotypes. The highest Spikelet panicle ${ }^{-1}$ (272) was recorded in HRDC 1311 and the lowest (114) in HRDC 1343 and 1349, respectively. The highest fertility \% (82.4) and 1000-grain wt. (28.85 g) was recorded in HRDC 1340 and 1313, respectively and the lowest $(49.9 \%$ and $12.90 \mathrm{~g}$ ) in HRDC 1311. Among the genotypes, the grain yield ranges between 2.48 and $5.65 \mathrm{t} \mathrm{ha}^{-1}$. The highest yield was observed in HRDC 1341 because of produced heaviest panicle and the lowest in HRDC 1311 because of obtained lowest fertility (\%) and 1000-grain wt., respectively.

On the basis of $\mathrm{D}^{2}$ values, by the application of non-hierarchical clustering using covariance matrix, the 43 genotypes were grouped into five clusters (Table 2). Among five clusters, cluster III had the maximum genotypes (15) followed by cluster V (13 genotypes) and the lowest was found from cluster I (1 genotype).

The inter-cluster distances in all the cases were greater than intra-cluster distances suggesting wider diversity among the genotypes of the distant groups (Table 3). Nayak et al. (2004) also found similar trends in rice. The intra-cluster degree of diversity was maximum in cluster III (1.73) indicating that the genotypes in cluster I was more heterogeneous and minimum in cluster I (0.00), since it consisted with one genotype. The maximum inter-cluster distances were observed between cluster I and V (11.63) followed by cluster I and III (10.86), cluster I and II (10.36), cluster II and V (8.46), and the minimum between cluster III and IV (2.35).

From Table 4, it is clearly observed that the highest mean values for fertility percentage, panicle weight and 1000 grain wt. but early flowering and short maturing genotypes were grouped into Cluster II followed by Cluster III and IV. Mean performance of different clusters also revealed that for number of plant height, days to $50 \%$ flowering, growth duration, panicle length, panicle weight, fertility $(\%)$ and 1000grain wt., cluster I and cluster II were the most diverged genotype groups. Again, cluster II and $\mathrm{V}$ were most diverged for panicle no. $\mathrm{m}^{-2}$, cluster III and IV for spikelet panicle ${ }^{-1}$ and cluster I and IV for grain yield.

Vector 1 obtained from PCA express that growth duration, spikelet panicle ${ }^{-1}$, fertility $(\%)$ and 1000 -grain wt. contributed to genetic divergence whereas in vector 2 , plant height, panicle no. $\mathrm{m}^{-2}$, spikelet panicle ${ }^{-1}$, fertility (\%) and 1000-grain wt. played important role in genetic divergence for having positive values (Table 5). Choudhury et al. (1999) also found that plant height contributed the highest for genetic divergence. Both the vectors had positive values for growth duration, spikelet panicle ${ }^{-1}$, fertility $(\%)$ and 1000-grain wt indicating the highest contributions of these traits towards the divergence among $F_{1}$ hybrid rice genotypes. 
Table 1. Mean performance of growth parameters, yield and yield components of HRDC genotypes during wet season over two locations

\begin{tabular}{|c|c|c|c|c|c|c|c|c|c|c|}
\hline Genotypes & YIELD & $\mathrm{PH}$ & $\mathrm{PM}^{-2}$ & FD & CGD & PL & PW & $\mathrm{SP}^{-1}$ & FER \% & TGW \\
\hline HRDC 1301 & 5.10 & 134 & 167 & 95 & 125 & 29.7 & 2.75 & 183 & 67.6 & 22.78 \\
\hline HRDC 1303 & 4.11 & 132 & 218 & 94 & 121 & 28.4 & 2.27 & 184 & 59.3 & 20.55 \\
\hline HRDC 1304 & 4.22 & 139 & 174 & 94 & 120 & 30.1 & 2.53 & 174 & 66.5 & 22.47 \\
\hline HRDC 1305 & 4.83 & 131 & 168 & 97 & 126 & 30.4 & 2.68 & 160 & 69.9 & 24.40 \\
\hline HRDC 1306 & 4.67 & 137 & 177 & 92 & 122 & 27.2 & 2.82 & 168 & 66.1 & 25.70 \\
\hline HRDC 1307 & 4.12 & 122 & 152 & 88 & 117 & 27.8 & 2.23 & 207 & 53.7 & 20.85 \\
\hline HRDC 1308 & 4.16 & 132 & 156 & 94 & 122 & 28.6 & 2.60 & 177 & 65.7 & 22.32 \\
\hline HRDC 1309 & 4.61 & 130 & 172 & 91 & 122 & 29.1 & 2.58 & 206 & 67.4 & 19.55 \\
\hline HRDC 1310 & 5.02 & 140 & 179 & 96 & 124 & 28.1 & 2.47 & 173 & 65.3 & 22.05 \\
\hline HRDC 1311 & 2.48 & 138 & 164 & 94 & 121 & 30.3 & 1.75 & 272 & 49.9 & 12.90 \\
\hline HRDC 1312 & 4.79 & 134 & 203 & 96 & 126 & 26.2 & 2.47 & 171 & 65.0 & 21.57 \\
\hline HRDC 1313 & 4.63 & 118 & 164 & 84 & 114 & 24.5 & 2.98 & 151 & 68.0 & 28.85 \\
\hline HRDC 1314 & 4.57 & 142 & 167 & 93 & 119 & 27.3 & 2.85 & 199 & 71.2 & 20.23 \\
\hline HRDC 1315 & 4.22 & 122 & 163 & 92 & 119 & 28.4 & 2.35 & 166 & 60.1 & 24.53 \\
\hline HRDC 1316 & 4.05 & 133 & 156 & 87 & 114 & 27.3 & 2.65 & 190 & 60.3 & 23.28 \\
\hline HRDC 1317 & 3.67 & 125 & 138 & 80 & 113 & 27.0 & 2.57 & 171 & 65.4 & 23.25 \\
\hline HRDC 1318 & 3.88 & 125 & 201 & 100 & 124 & 27.1 & 2.45 & 193 & 69.0 & 18.87 \\
\hline HRDC 1319 & 4.18 & 130 & 199 & 102 & 128 & 24.8 & 2.18 & 170 & 63.8 & 19.83 \\
\hline HRDC 1324 & 4.38 & 140 & 157 & 94 & 122 & 29.3 & 2.30 & 165 & 61.0 & 23.10 \\
\hline HRDC 1325 & 4.64 & 136 & 185 & 88 & 116 & 28.5 & 2.57 & 158 & 68.8 & 24.15 \\
\hline HRDC 1326 & 4.20 & 143 & 198 & 91 & 119 & 30.5 & 1.95 & 171 & 52.1 & 21.50 \\
\hline HRDC 1327 & 4.16 & 125 & 163 & 82 & 119 & 27.3 & 2.10 & 131 & 62.8 & 25.27 \\
\hline HRDC 1328 & 4.55 & 124 & 165 & 91 & 121 & 26.5 & 2.40 & 154 & 62.6 & 25.47 \\
\hline HRDC 1329 & 4.17 & 124 & 168 & 91 & 121 & 25.7 & 2.75 & 173 & 59.7 & 26.38 \\
\hline HRDC 1330 & 5.13 & 130 & 162 & 93 & 120 & 26.1 & 2.50 & 199 & 61.8 & 21.17 \\
\hline HRDC 1331 & 3.78 & 127 & 161 & 91 & 118 & 28.9 & 2.75 & 208 & 68.5 & 20.05 \\
\hline HRDC 1332 & 4.66 & 126 & 170 & 91 & 119 & 30.1 & 2.30 & 197 & 59.8 & 19.70 \\
\hline HRDC 1333 & 4.30 & 136 & 158 & 90 & 118 & 29.1 & 2.63 & 211 & 57.1 & 21.95 \\
\hline HRDC 1334 & 3.91 & 117 & 197 & 88 & 116 & 26.0 & 2.22 & 162 & 60.4 & 23.55 \\
\hline HRDC 1335 & 5.06 & 137 & 194 & 86 & 114 & 27.2 & 2.20 & 157 & 62.5 & 22.98 \\
\hline HRDC 1336 & 4.13 & 127 & 170 & 80 & 116 & 25.7 & 2.68 & 172 & 66.8 & 23.07 \\
\hline HRDC 1338 & 4.97 & 139 & 199 & 91 & 120 & 27.6 & 2.58 & 177 & 60.8 & 24.63 \\
\hline HRDC 1339 & 4.77 & 131 & 211 & 91 & 120 & 29.3 & 2.22 & 139 & 64.5 & 25.07 \\
\hline HRDC 1340 & 4.63 & 116 & 131 & 82 & 115 & 25.9 & 3.63 & 172 & 82.4 & 26.80 \\
\hline HRDC 1341 & 5.65 & 131 & 160 & 87 & 115 & 25.8 & 4.28 & 208 & 78.1 & 26.40 \\
\hline HRDC 1342 & 3.78 & 113 & 214 & 81 & 118 & 27.7 & 1.95 & 150 & 54.9 & 23.88 \\
\hline HRDC 1343 & 5.32 & 124 & 225 & 94 & 124 & 28.6 & 2.02 & 114 & 72.6 & 24.43 \\
\hline HRDC 1347 & 3.26 & 123 & 200 & 89 & 122 & 28.3 & 2.17 & 154 & 54.7 & 24.78 \\
\hline HRDC 1349 & 2.86 & 108 & 161 & 80 & 117 & 25.5 & 1.47 & 114 & 53.4 & 23.97 \\
\hline HRDC 1350 & 2.99 & 124 & 239 & 85 & 119 & 27.0 & 1.80 & 138 & 53.2 & 24.73 \\
\hline Aloran & 4.44 & 125 & 154 & 84 & 113 & 26.2 & 2.77 & 144 & 70.7 & 27.37 \\
\hline
\end{tabular}




\begin{tabular}{|c|c|c|c|c|c|c|c|c|c|c|}
\hline Continued & & & & & & & & & & \\
\hline BRRI dhan39 & 4.45 & 127 & 157 & 87 & 120 & 27.1 & 2.57 & 143 & 76.9 & 23.45 \\
\hline Shakti-2 & 3.99 & 134 & 145 & 79 & 114 & 25.0 & 3.22 & 196 & 64.0 & 25.63 \\
\hline $\mathrm{LSD}_{0.05}$ & 1.38 & 7 & 40 & 10 & 12 & 0.45 & 0.78 & 33 & 12.59 & 0.93 \\
\hline MEAN & 4.31 & 129 & 176 & 89 & 119 & 27.6 & 2.49 & 173 & 63.8 & 23.10 \\
\hline Minimum & 2.48 & 108 & 131 & 79 & 113 & 24.5 & 1.47 & 114 & 49.9 & 12.90 \\
\hline Maximum & 5.65 & 143 & 239 & 102 & 128 & 30.5 & 4.28 & 272 & 82.4 & 28.85 \\
\hline
\end{tabular}

Legend: $\mathrm{PH}=$ Plant height, $\mathrm{FD}=$ Days to $50 \%$ flowering, $\mathrm{CGD}=$ Crop growth duration, $\mathrm{PL}=\mathrm{Panicle}$ length, $\mathrm{PW}=$ Panicle weight, $\mathrm{SP}^{-1}=$ Spikelet panicle ${ }^{-1}$, FER $\%=$ Fertility $\%$ and TGW= 1000-grain wt.

Table 2. Distribution of HRDC genotypes to different clusters as determined by multivariate analysis during wet season over two locations

\begin{tabular}{|c|c|c|c|}
\hline Cluster & $\begin{array}{l}\text { Serial No. of the } \\
\text { genotypes }\end{array}$ & $\begin{array}{c}\text { No. of } \\
\text { genotypes }\end{array}$ & Name of genotypes \\
\hline I & G10 & 1 & HRDC 1311 \\
\hline II & G16 and G34 & 2 & HRDC 1317 and HRDC 1340 \\
\hline III & $\begin{array}{l}\text { G3, G4, G5, G9, G12, } \\
\text { G14, G19, G20, G22, } \\
\text { G23, G24, G31. G39, } \\
\text { G41 and G42 }\end{array}$ & 15 & $\begin{array}{l}\text { HRDC 1304, HRDC 1305, HRDC 1306, HRDC } \\
\text { 1310, HRDC 1313, HRDC 1315, HRDC 1324, } \\
\text { HRDC 1325, HRDC 1327, HRDC 1328, HRDC } \\
\text { 1329, HRDC 1336, HRDC 1349, Aloran and } \\
\text { BRRI dhan39 }\end{array}$ \\
\hline IV & $\begin{array}{l}\text { G1, G6, G7, G8, G13, } \\
\text { G15, G25, G26, G27, } \\
\text { G28, G35 and G43 }\end{array}$ & 12 & $\begin{array}{l}\text { HRDC 1301, HRDC 1307,HRDC 1308, HRDC } \\
\text { 1309, HRDC 1314, HRDC 1316, HRDC 1330, } \\
\text { HRDC 1331, HRDC 1332, HRDC 1333, HRDC } \\
1341 \text { and Shakti-2 }\end{array}$ \\
\hline V & $\begin{array}{l}\text { G2, G11, G17, G18, } \\
\text { G21, G29, G30, G32, } \\
\text { G33, G36, G37, G38 } \\
\text { and G40 }\end{array}$ & 13 & $\begin{array}{l}\text { HRDC 1303, HRDC 1312, HRDC 1318, HRDC } \\
\text { 1319, HRDC 1326, HRDC 1334, HRDC 1335, } \\
\text { HRDC 1338, HRDC 1339, HRDC 1342, HRDC } \\
\text { 1343, HRDC } 1347 \text { and HRDC } 1350\end{array}$ \\
\hline
\end{tabular}

Table 3. Intra (bold) and inter-cluster distance $\left(\mathrm{D}^{2}\right)$ of HRDC genotypes during wet season over two locations

\begin{tabular}{cccccc}
\hline Cluster & I & II & III & IV & V \\
\hline I & $\mathbf{0 . 0 0}$ & & & & \\
II & 10.36 & $\mathbf{0 . 2 5}$ & & & \\
III & 10.86 & 4.23 & $\mathbf{1 . 7 3}$ & & \\
IV & 8.64 & 3.44 & 2.35 & $\mathbf{0 . 8 2}$ & $\mathbf{1 . 0 9}$ \\
V & 11.63 & 8.46 & 4.34 & 5.50 & $\mathbf{1 . 5 0}$ \\
\hline
\end{tabular}


Table 4. Cluster means for ten characters of HRDC genotypes during wet season over two locations

\begin{tabular}{|c|c|c|c|c|c|}
\hline \multirow[t]{2}{*}{ Traits } & \multicolumn{5}{|c|}{ Clusters means } \\
\hline & $\mathrm{I}$ & II & III & IV & $\mathrm{V}$ \\
\hline Yield $\left(\mathrm{t} \mathrm{ha}^{-1}\right)$ & 2.48 & 4.15 & 4.36 & 4.51 & 4.25 \\
\hline Plant height $(\mathrm{cm})$ & 138 & 120 & 128 & 131 & 129 \\
\hline Panicle no. $\mathrm{m}^{-2}$ & 164 & 134 & 167 & 160 & 208 \\
\hline Days to $50 \%$ flowering & 94 & 81 & 89 & 90 & 91 \\
\hline Growth duration (days) & 121 & 114 & 119 & 119 & 121 \\
\hline Panicle length $(\mathrm{cm})$ & 30.33 & 26.45 & 27.41 & 27.93 & 27.63 \\
\hline Panicle weight (g) & 1.75 & 3.10 & 2.50 & 2.78 & 2.19 \\
\hline Spikelet panicle $^{-1}$ & 198 & 171 & 156 & 272 & 160 \\
\hline Fertility (\%) & 49.97 & 73.98 & 65.28 & 64.64 & 61.02 \\
\hline 1000-grain wt. (g) & 12.90 & 25.03 & 24.68 & 22.80 & 21.99 \\
\hline
\end{tabular}

Table 5. Relative contributions of the ten characters to the total divergence in HRDC genotypes during wet season over two locations

\begin{tabular}{lcc}
\hline Traits & Vector 1 & Vector 2 \\
\hline Yield $\left(\mathrm{t} \mathrm{ha}^{-1}\right)$ & -0.191 & -0.3114 \\
Plant height $(\mathrm{cm})$ & -0.0106 & 0.0163 \\
Panicle no. ${ }^{-2}$ & -0.089 & 0.042 \\
Days to 50\% flowering & -0.1271 & -0.1121 \\
Growth duration (days) & 0.1073 & 0.104 \\
Panicle length (cm) & 0.2524 & -0.0843 \\
Panicle weight (g) & -2.9262 & -5.9803 \\
Spikelet panicle & 0.0719 & 0.1342 \\
Fertility (\%) & 0.1705 & 0.2118 \\
1000-grain wt. (g) & 0.3458 & 0.5889 \\
\hline
\end{tabular}

Table 6. Eigen values and yield percent contribution of 10 characters of HRDC genotypes during wet season over two locations

\begin{tabular}{cccc}
\hline Principle component (PC) & Eigen values & Percent variation & $\begin{array}{c}\text { Cumulative \% of Percent } \\
\text { variation }\end{array}$ \\
\hline PC 1 & 1.7757 & 35.61 & 35.61 \\
PC 2 & 1.6924 & 33.94 & 69.55 \\
PC 3 & 0.7685 & 15.41 & 84.96 \\
PC4 & 0.2751 & 5.52 & 90.48 \\
PC 5 & 0.2202 & 4.42 & 94.90 \\
PC 6 & 0.1056 & 2.12 & 97.02 \\
PC 7 & 0.0765 & 1.53 & 98.55 \\
PC 8 & 0.0614 & 1.23 & 99.78 \\
PC 9 & 0.0082 & 0.17 & 99.95 \\
PC 10 & 0.0025 & 0.05 & 100.00 \\
\hline
\end{tabular}




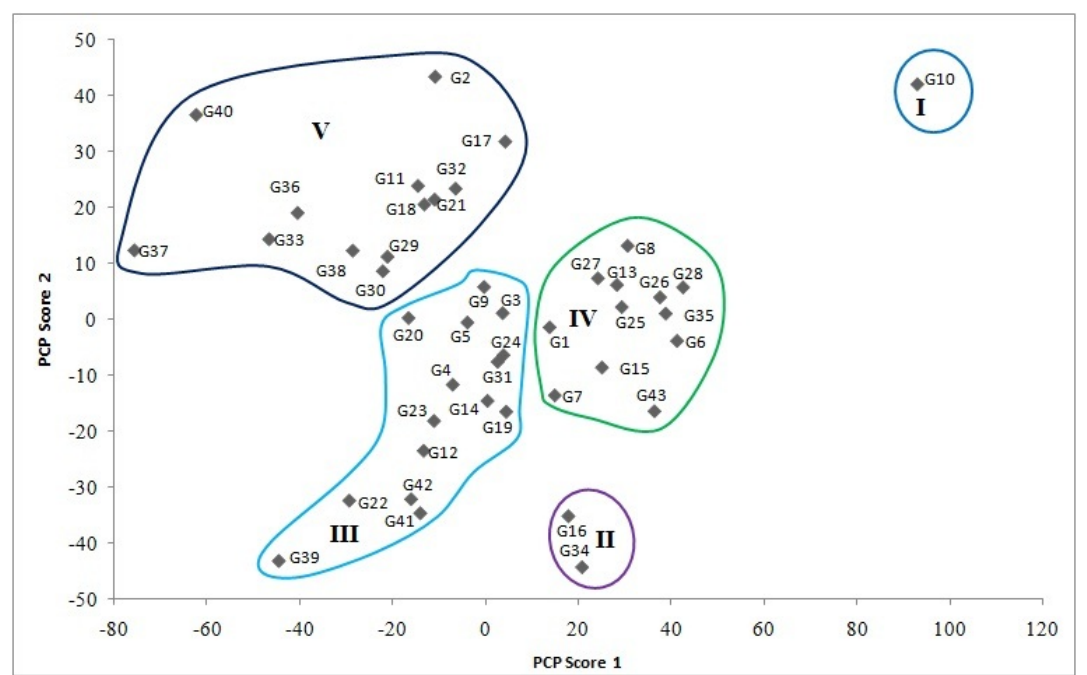

Figure 1. Distribution of 43 genotypes of transplanted Aman rice in a two-dimensional Scatter diagram based on PCA scores superimposed with clusters

The PC 1 and 2 had $35.61 \%$ and $33.94 \%$ variability among the genotypes for the evaluated traits, respectively. Eigen values associated with each PC, decreased gradually and stopped at 0.0025 (Table 6). On the basis of the principal axes I and II, a two dimension scatter diagram was prepared showing the groups into five clusters of genotypes (Figure 1). The principal component analysis (PCA) showed that the first two components accounted for $69.55 \%$ of the total variation and a two dimensional scatter diagram was constructed using component 1 as $\mathrm{X}$-axis and component 2 as $\mathrm{Y}$ axis, reflecting the relative positions of the genotypes. The clustering pattern observed from $\mathrm{D}^{2}$ analysis was also reflected by this diagram.

\section{Conclusions}

The overall results showed that Shakti-2 and Aloran was short maturing but the highest grain yield was observed in HRDC 1341 among the tested rice genotypes. Wider genetic diversity among the genotypes of the distant groups was observed. The genotypes under cluster IV gave the highest yield because of produced higher spikelet panicle ${ }^{-1}$ than other clusters. The highest mean values for fertility percentage, panicle weight and 1000 grain wt. but early flowering and short maturing genotypes were grouped into Cluster II, III and IV. The genotypes under these clusters should therefore be selected, and their seed production feasibility in local condition should be studied before making final selection to submit in SCA trials as wet season hybrid in Bangladesh.

\section{References}

Akhter, Z., Shamsuddin, A. K. M., Rohman, M. M., Shalim Uddin, M., Mohi-Ud-din, M. and Alam, A. K. M. M. 2003. Studies on heterosis for yield and yield components in wheat. Journal of Biological Sciences, 3:892-897.

BBS (Bangladesh Bureau of Statistics). 2011. Statistical Year Book of Bangladesh 2011. Bangladesh Bureau of Statistics Division, Ministry of Planning, Govt. of the People's Republic of Bangladesh, Dhaka. 
BBS. 2012. Estimates of Aman Rice, 2011-2012. Agriculture wing, Parishankhyan Bhaban E-27/A, Agargaon, Dhaka-1207 www.bbs.gov.bd.

Bhuiyan, N. I. 2002. The Hybrid Rice Programme for Bangladesh. In: "Hybrid Rice in Bangladesh: Progress and Future Strategies". 3-5 pp. Bangladesh Rice Research Institute, Publication No. 138.

Belaj, A., Satovic, Z., Rallo L. and Trujillo, I. 2002. Genetic diversity and relationship in olive (Olea europea L.) germplasm collection as determined by RAPD. Theoretical and Applied Genetics, 105: 638-644.

Chen, M., Huang, J., Cui, K., Nie, L. and Shah, F. 2009. Genotypic variations in terms of $\mathrm{NH}_{3}$ volatilization in four rice (oryza sativa L.) cultivars. Asian Journal of Plant Sciences, 8:353-360.

Choudhury, D. A., Hamid, A., Bhowmik, A., Mian, G. U. and Islam, M. S. 1999. Genetic divergence in indigenous rice (oryza sativa L.) varieties of Bangladesh. Bangladesh Journal of Plant Breeding and Genetics, 12 (1\& 2):33-36.

Degenkolbe, T., Zuther, P. T. E., Repsilber, D., Walther, D., Hincha, D. K. and Koul, K. I. 2009. Expression profiling of rice cultivars differing in their tolerance to long-term drought stress. Plant Molecular Biology, 69:133-153.

Haque, M. M. and Biswas, J. K. 2011. Annual Research Review. Plant Physiology Division. Bangladesh Rice Research Institute, Joydebpur, Gazipur, Bangladesh.

IRRI. 2002. Standard Evaluation System for Rice. International Rice Research Institute, Manila, Philippines.
Julfiquar, A. W., Hassan, M. J., Azad, A. K. and Nurunnabi, N. 2002. Research and Development of hybrid rice in Bangladesh. Bangladesh Rice Research Institute, Gazipur-1701, Bangladesh, 9-19 pp.

Lanceras, J. C., Pantuwan, G., Jongdee, B. and Toojinda, T. 2004. Quantitative trait loci associated with drought tolerance at reproductive stage in rice. Plant Physiology, 135:384-399.

Mahalanobis, P. C. 1936. On the generalized distance in statistics. Proc. of the National Institute of Sciences of India, 2: 49-55.

Masum, M. 2009. Impact of hybrid rice in Bangladesh. In: "The Guardian". Vol. XIX. Issue 3.3: 56-58 pp.

Nayak, A. R., Chaudhary, D. and Reddy, J. N. 2004. Genetic divergence in scented rice. Oryza, 41(3-4):79-82.

Peng, S., Yang, J., Laza, R. C., Sanico, A. L., Visperas, R. M. and Song, T. T. 2003. Physiological bases of heterosis and crop management strategies for hybrid rice in the tropics. In: Virmani, S. S., Mao, C. X. and Dardy, B. (eds.) Hybrid Rice for Food Security, Poverty Alleviation, and Environment Protection. Proc. of the 4th International Symposium on Hybrid Rice, 14-17 May 2002, Hanoi, Vietnam. Los Baños (Philippines): International Rice Research Institute, 153-170 pp.

Tiwari, D. K., Pandey, P., Giri, S. P. and Dwivedi, J. L. 2011. Heterosis studies for yield and its components in rice hybrids using CMS system. Asian Journal of Plant Sciences, 10:29-42.

Ward, J. H., Jr. 1963. "Hierarchical Grouping to Optimize an Objective Function". Journal of the American Statistical Association, 58:236-244. 